\title{
APRENDER A LER O TEMPO: UMA HISTÓRIA SOBRE O ENSINO DAS MUDANÇAS CLIMÁTICAS E A PERCEPÇÃO DA NATUREZA
}

\author{
LEARNING TO READ THE TIME: A HISTORY ABOUT \\ TEACHING CLIMATE CHANGE AND THE \\ PERCEPTION OF NATURE
}

Denise Bernuzzi de Sant'Anna ${ }^{1, *}$ (iD

\begin{abstract}
RESUMO: Este artigo vista contribuir para o entendimento das relações históricas entre variações climáticas e emoções humanas. A intenção principal é a de perceber algumas mudanças ocorridas na leitura do clima presentes em livros escolares de geografia e na primeira revista infantil brasileira, intitulada Tico-Tico. Trata-se do resultado de uma pesquisa mais ampla sobre as relações entre clima e melancolia, na qual as transformações das sensibilidades nos modos de perceber as estações do ano e as características atmosféricas relacionam-se intimamente com o perfil das emoções e a sua história.
\end{abstract}

Palavras-chave: Clima. Educação. História das sensibilidades.

\begin{abstract}
This article aims to contribute to the understanding of the historical relations between climatic variations and emotions. The main intention is to perceive some changes that occurred regarding what people could read about the climate in school books of geography and the first Brazilian children's magazine, Tico-Tico. This is the result of a broader research on the relationship between climate and melancholia, in which the transformations of sensibilities in the ways of perceiving the seasons and the atmospheric characteristics are closely related to the profile emotions and their history.
\end{abstract}

Keywords: Climate. Education. History of sensibilities.

\footnotetext{
1.Pontifícia UniversidadeCatólica deSão Paulo-DepartamentodeHistóriadaFaculdadedeCiênciasSociaisSão Paulo (SP), Brasil.

*Autora correspondente: dbsat@uol.com.br

Este texto resulta de uma pesquisa financiada pelo CNPq, bolsa produtividade. Sua elaboração também teve o apoio do Programa PEPG de Excelência da PUC-SP em 2019.

Dossiê organizado por: Carmen Lucia Soares e Heloísa Helena Pimenta Rocha
} 


\section{Clima e Emoções: Algumas Notas Bibliográficas}

A obra célebre de Emmanuel Le Roy Ladurie (1967) sobre a história do clima representou uma importante contribuição para os historiadores interessados em compreender as influências recíprocas entre vida humana e meio ambiente. Ela faz parte de uma tendência mais ampla, típica das décadas de 1960 e 1970, quando uma consciência ecológica se desenvolveu dentro e fora dos limites científicos, alcançando os meios de comunicação de massa e modificando as maneiras de ensinar crianças e jovens a perceber o tempo e o clima. A partir dela, a história do meio ambiente recebeu numerosas contribuições, incluindo os estudos sobre a meteorologia e as suas relações com a construção da subjetividade.

Entre esses estudos, destacam-se os livros do historiador Alain Corbin, sobre as emoções diante das mudanças climáticas, principalmente a partir do final do século XVIII. Segundo Corbin (2013), nessa época, houve a emergência de uma "alma sensível", para a qual a magnificência da natureza correspondia à grandeza dos sentimentos humanos, enquanto que os abalos meteorológicos eram expressivos dos arrebatamentos do desejo. Na mesma direção, o historiador romeno Lucian Boia (2005) defendeu que as relações dos humanos com o clima não começaram com o advento do aquecimento global, ao contrário, trata-se de um problema antigo, com vários pontos de inflexão. Boia lembrou que a análise do imaginário relacionado ao clima representa uma maneira privilegiada de conhecer os medos e os sonhos de cada época ou, ainda, as emoções alegres e tristes. William Reddy (2001), outro autor bastante conhecido na área, assinalou que, desde o final do século XVIII, houve o florescimento de emoções coletivas, embaladas pelo sentimento revolucionário, quando, então, um novo regime sentimental foi instituído. Nesse momento, o termo "cenestesia", trabalhado cientificamente pelo médico alemão Johann Christian Reil em 1794, passou a marcar presença na obra de diversos escritores e filósofos interessados em compreender as influências das variações meteorológicas no organismo e nos sentimentos humanos.

Esses pesquisadores inserem-se numa rica tradição de estudos sobre a história das emoções que, especialmente após 1980, foi significativamente ampliada e renovada. Uma tradição que remonta aos trabalhos de Lucien Febvre (1941), historiador preocupado com as sensibilidades de épocas passadas e que lançou o desafio de estudá-las. Mais tarde, o uso do conceito "emoção" passou a ser inserido no terreno histórico das sensibilidades e, desde então, as perspectivas de autores como Corbin, Reddy ou Rosenwein confirmaram a necessidade de problematizar os sentimentos do passado. Assim, por exemplo, conforme Rosenwein (2011), tanto quanto os estudos sobre gênero, aqueles voltados às emoções de outras épocas e culturas fornecem subsídios fundamentais para a compreensão do presente. Outra contribuição recente e importante ao tema é a coleção em três volumes, publicada na França, intitulada Histoire des émotions (CORBIN et al., 2016). Esses volumes reúnem textos de alguns dos principais especialistas na área e consolida o campo da história das emoções dentro dos cursos e publicações de historiadores (SANT’ANNA, 2016).

A partir dessa perspectiva, o entendimento da associação entre clima, emoções e meteorologia também representou um passo inovador para o estudo das emoções. Wladimir Jankovic (2000), por exemplo, com a obra Reading the skies: A cultural history of English weather, 1650-1820, traça uma história das maneiras de interpretar o clima e, sobretudo, de ler os céus, mostrando o quanto essa experiência permaneceu durante séculos fora dos domínios de uma ciência global. Já o livro de Jon Golinski (2007), intitulado British weather and the climate of enlightenment, propõe uma análise histórica não apenas da meteorologia, mas também das relações entre os saberes que a circundavam na Inglaterra do século XVIII. É quando o registro do que se passa na atmosfera revela ser uma oportunidade para expressar as subjetividades e, também, para disciplinar o corpo. Os progressos na fabricação do barômetro destacam-se nessa antiga necessidade de prever mudanças climáticas e também de interpretá-las a partir das vicissitudes humanas. Ao mesmo tempo, a experiência 
do sublime junto às montanhas e ao litoral abriu-se à possibilidade de tratar doenças físicas e psíquicas, sustentada pelo vitalismo interessado em restaurar o equilíbrio das fibras nervosas, sobre as quais repousaria a sensibilidade. Já aparece aqui uma mudança de paradigma importante em relação ao corpo, diferente dos ideais mecanicistas em voga no começo da era moderna. A partir do Século das Luzes, emerge o ideal de um corpo atravessado por nervos, assim como um "foro íntimo" relacionado à fisiologia de cada indivíduo (VIGARELLO, 2014, p. 80).

Embora a suposição de que as mudanças climáticas possam influir decisivamente sobre as emoções humanas não seja uma novidade histórica e tenha se adensado no final do século XVIII, foi no decorrer do período seguinte que uma série de registros sobre a referida "alma sensível" - especialmente na pintura, na música e na literatura - se tornou uma marca registrada da cultura ocidental. Ou seja, no século XIX, em meio à difusão de uma sensibilidade aguçada diante das variações atmosféricas e de sua incorporação a uma visão romântica do mundo, a história das maneiras de perceber e de ler o tempo participaram cada vez mais amplamente da ciência e da interiorização de sistemas meteorológicos outrora inexistentes. Além disso, o século XIX foi um período de grandes progressos na climatologia e na meteorologia, incluindo desde a difusão dos anuários de meteorologia de Jean-Baptiste Lamarck até os trabalhos de Charles-Alfred Angot que, segundo Emmanuel Le Roy Ladurie, foi um dos pais da climatologia moderna (LADURIE, 1967).

A mesma tendência se fez sentir no Brasil do período imperial. A imprensa nacional publicava, por um lado, inúmeros textos expressivos de um romantismo ancorado nas variações das estações do ano, da temperatura, dos ventos e chuvas. Por outro, a mesma imprensa difundia as previsões meteorológicas que não tardaram a servir aos interesses da economia agrícola e à navegação. Contudo, a partir da segunda metade do século XIX, principalmente, aumentou de modo inusitado o número de estudos científicos sobre os fenômenos naturais no país. O ensino de Geografia estabeleceu-se como ciência escolar e disciplina obrigatória, ao mesmo tempo em que novas técnicas de mensuração das variações atmosféricas foram estabelecidas mundialmente. As relações entre meteorologia e emoções humanas se intensificaram e se mostraram essenciais à caracterização dos temperamentos em obras literárias, mas também em tratados científicos. Desde então, uma nova consciência relativa às consequências do progresso tecnológico e do desenvolvimento urbano sobre a saúde do planeta e dos seres que nele vivem pôde ser construída, mostrando aos humanos o quanto ainda há a ser feito para preservar as diferentes formas de vida na Terra.

Ainda no século XIX, a influência do clima sobre as tristezas tornou-se evidente no meio científico, com a divulgação de teses médicas que tentavam comprovar as relações entre temperamentos, identidades e variações climáticas. Entre os primeiros exemplos brasileiros a este respeito, destaca-se a tese de Joaquim Manoel de Macedo intitulada Considerações sobre a nostalgia, defendida na Faculdade de Medicina do Rio de Janeiro em 1844. Para Macedo,

[...] há um tempo e um espaço no mundo exterior que devem ser mais propícios à gestação da nostalgia. E tanto o tempo como o espaço são realidades naturais e humanas. É da ocorrência ou conjugação de um certo lugar, um certo clima e um certo estágio de desenvolvimento pessoal e social que surge com mais frequência a saudade da pátria. (POLITO; LOPES, 2004, p. 129)

No mesmo ano em que Macedo defendeu a sua tese sobre a nostalgia, o médico francês José Francisco Xavier Sigaud publicou o livro Du climat et des maladies du Brésil ou statistique médicale de cet empire (SIGAUD, 1844). Nele, Sigaud mostrou o levantamento que realizou das doenças e do clima brasileiros contribuindo para afirmar a relação entre patologias do corpo e especificidades climáticas. Essa correlação 
permaneceu forte ao longo do século XIX, justamente quando ocorria, em diversas sociedades europeias, um aumento inusitado do uso da palavra emoção na literatura e também em obras científicas. Foi nesse período que a atenção ao clima se tornou mais técnica e científica, ganhando páginas na imprensa diária de diferentes países. No Brasil, desde a criação do Observatório Astronômico Imperial do Rio de Janeiro, em 1827, diversos procedimentos científicos tiveram início e estão na origem da climatologia nacional. Na segunda metade do século XIX, o Observatório começou a publicar os “Anais meteorológicos”, enquanto que as teorias científicas europeias sobre a atmosfera não tardaram a influenciar os pesquisadores brasileiros. Mais tarde, em 1909, foi criado o Instituto Nacional de Meteorologia (INMET), pelo Decreto 7.672, do presidente Nilo Peçanha, com o nome de Diretoria de Meteorologia e Astronomia. Era um órgão do Observatório Nacional, vinculado ao Ministério da Agricultura, Indústria e Comércio.

Contudo, no final do século XIX, somente na Europa, as previsões de tempo eram feitas de forma sistemática. Naquela época, a meteorologia era uma ciência basicamente observacional, as previsões possuíam pouca confiabilidade e eram realizadas para um prazo máximo de 24 horas.

\section{O Clima e o Enfoque Paulista}

Entre os vários exemplos brasileiros a respeito das relações entre emoções e clima, a cidade de São Paulo ocupa um lugar de destaque. Entre 1870 e 1930, a capital paulista sofreu uma radical transformação de sua paisagem natural e transformou-se em uma metrópole que reunia comerciantes, empresários, engenheiros, cientistas e políticos com ambições de liderar o progresso nacional. Entretanto o frio, o calor e as chuvas, eram constantemente lembrados pela imprensa local e em discussões das Atas da Câmara desde o final do Império. O determinismo climático e o determinismo racial pesavam nas hipóteses de uma parte significativa da elite letrada nacional.

Ora, foi principalmente nesse período de sedução pela retórica cientificista, influenciada pelas teorias raciais presentes na Europa de meados século XIX, que as elites econômicas paulistas expressaram suas ambições em afirmar explicações ligadas ao meio e à raça para diferenciar laboriosos de ociosos, virtuosos de viciosos, civilizados de selvagens. Trata-se de uma época com um significativo predomínio econômico e político daquelas elites, mas também de uma proliferação de textos na imprensa paulista que enfatizavam a íntima influência do clima da cidade nas maneiras de viver e de sentir de seus habitantes. O período representa um momento histórico que favoreceu a progressiva popularização da sensibilidade à meteorologia consultada comumente no século XX ou, ainda, a uma cultura da previsão diária do tempo, unida à suposição de que as condições atmosféricas devem ser não apenas medidas e previstas, mas sobretudo mantidas como provas da civilização coletiva e da sensatez individual.

Importante, também, foram as informações meteorológicas feitas pela Companhia Cantareira e Esgotos, desde 1880, e divulgadas pela imprensa local. Além disso, a partir de 1886, a Comissão Geográfica e Geológica de São Paulo começou a publicar os dados meteorológicos das primeiras estações implementadas no estado (SANT'ANNA NETO, 2001). Os trabalhos da comissão foram essenciais para a institucionalização da climatologia no país e contribuíram para modificar a percepção do clima exposta em jornais e revistas da capital. Segundo Sant'Anna Neto (2001, p. 16), a rede paulista utilizava aparelhos análogos aos europeus e, em 1900, ela "já contava com cerca de 40 estações meteorológicas espalhadas em seu território".

Enquanto isso, na imprensa paulista, a chuva tendia a ser concebida como uma espécie de barômetro privilegiado das emoções tristes e de uma certa identidade dos habitantes locais. Comentários que exprimem a relação entre tristeza e tempo chuvoso não eram uma exceção: "A semana pertenceu quasi exclusivamente 
á chuva, o que é o mesmo que dizer que decorreu ella triste, aborrecida, enfadonha. [...] Fallemos sério. São Paulo está triste" ${ }^{\prime}$.

As estações chuvosas costumavam provocar enchentes e evidenciar a necessidade de melhores trabalhos no calçamento da cidade, na construção de pontes e manutenção da salubridade das várzeas. Mas, além desses problemas urbanos, as chuvas também tendiam a ser associadas aos sentimentos de tristeza ou de revolta, distinguindo pessoas e temperamentos: "Há gente que não gosta da chuva e que, apenas o firmamento ennubla-se, enfurecem a cara e as ideias, e põe-se a pensar em cousas tristes" ${ }^{2}$.

Se a chuva sempre foi essencial à frutificação da vida, o imaginário que acompanha a sua presença não deixou de ser atravessado por experiências de apatia e recolhimento. Ao mesmo tempo, o espectro do dilúvio reenviava a imaginação ao temor das catástrofes naturais e das grandes cosmogonias. No começo de 1900, por exemplo, as chuvas fortes provocaram desabamentos e enchentes na capital paulista. Várias manifestações de medo diante da ameaça do dilúvio e do fim do mundo foram registradas pelos escritores locais, confirmando antigas superstições que relacionam catástrofe natural e manifestação divina (PRADO, 1963). Além disso, em São Paulo, a melancolia ligada à garoa, a malemolência quase entediada, típica das "épocas calmosas", ou ainda a saudade de uma outra terra e de pessoas amadas, despertada por neblinas ou pelo outono, revelavam não apenas o quanto eram diversificadas as "paisagens climáticas" da cidade, mas também como era importante recorrer a tais paisagens para expressar os sentimentos de natureza universal, comuns também em outras cidades e em diferentes países.

Não demorou muito para que as relações entre ensino escolar e uma nova sensibilidade referente à importância do clima e da meteorologia se afirmassem no universo infantil e juvenil, assim como na mentalidade de professores, escritores e educadores, comprometidos com a ordem e a higiene do país.

\section{Terra: Uma Mãe Forte, Selvagem e Imprevisível}

Foi sobretudo a partir do século XX que ensinar a leitura dos sinais do clima de cada região do país se tornou uma peça-chave na educação nacional. Tanto no domínio escolar como na imprensa, a tendência crescente foi a de considerar a meteorologia um tema a ser aprendido e difundido como parte integrante dos conhecimentos científicos e geográficos do Brasil.

Assim, por exemplo, em 1907, a revista infantil chamada Tico-Tico publicou uma estória, em vários capítulos, intitulada "Viagens maravilhosas do Dr. Alpha", de Oswaldo Silva. Trata-se de uma revista infantil, pioneira no Brasil, que começou a ser publicada em outubro de 1905. Chegou a ter uma tiragem de 100.000 exemplares por semana. Além de histórias em quadrinhos, a Tico-Tico continha lições de civismo, geografia, história, ciências, artigos, contos, mapas e conselhos. A partir de 1930, a revista foi influenciada por personagens dos quadrinhos norte-americano e foi publicada até a década de 1960 (BIBLIOTECA NACIONAL DIGITAL, 2015). Nela buscava-se ensinar o leitor o que significava sair da atmosfera terrestre, assim como o significado dos meteoros e dos cometas. A narrativa perguntava se havia atmosfera no mundo lunar, além de mencionar algumas características de planetas como Marte e Júpiter ${ }^{3}$. Marte era considerado o planeta com atmosfera semelhante à nossa, o que dava motivo à suspeita de que pudesse haver vida marciana ${ }^{4}$. A atmosfera também indicava chuvas próximas ou secura do ar. Os pássaros ainda eram importantes barômetros dos brasileiros, justamente numa época em que a população rural ainda era maior do que a urbana.

Durante as três primeiras décadas do século passado, entre os temas mais recorrentes em lições e textos de geografia e ciências da Tico-Tico, a atmosfera era um objeto de estudo frequente. Neles era mostrado, por exemplo, como o pó tem a capacidade de ficar suspenso no ar e o quanto este pode ser o meio ideal para 
transmitir doenças. Vários textos explicavam que as gotículas de água suspensas na atmosfera ocasionavam o arco-íris. A atmosfera que rodeia a terra, também chamada de "couraça salvadora", tendia a ser bastante valorizada na maior parte das explicações veiculadas pela Tico-Tico.

Na seção consagrada às "Lições do Vovô", a atmosfera também era um tema recorrente. Nela, as crianças aprendiam desde o fato de que as sanguessugas são muito sensíveis às mudanças atmosféricas, até a importância do cata-vento e os tipos de nuvens existentes no céu. A atmosfera, carregada de eletricidade, também podia indicar as tempestades vindouras, conforme os ensinamentos do Vovô. O mesmo ainda sublinhava o que pode ser uma ilusão de ótica causada pela reverberação do calor solar na areia e o que se passa nas camadas mais altas da atmosfera, elevando a imaginação das crianças para os mistérios do cosmos.

Na maior parte dos textos da Tico-Tico havia um encantamento com a grandiosidade e a riqueza das forças naturais. Estas constituíam a matéria-prima dos ensinamentos, ou seja, a natureza era o sujeito dos textos, seu personagem central, o lugar de todos os mistérios, envolvendo um conjunto de fenômenos diante dos quais os adultos e as crianças não tinham meios de controlar nem intervir. O planeta Terra tendia a ser visto como um conjunto de forças inesgotáveis e imprevisíveis, uma realidade mais selvagem do que domesticada.

Essa tendência se repete em livros escolares do período. A partir da década de 1920, a geografia escolar de influência francesa e alemã tendeu a modificar as maneiras de ler o tempo. Contudo a ideia de que todo o planeta possui pontos de contrastes violentos se manteve forte, formando a imagem de que a Terra é um lugar de tempestades, maremotos, furacões, "impetuosidades naturais" que ainda não podiam ser previstas nem controladas. A definição da atmosfera aparecia nos livros escolares como sendo uma espessa camada gasosa, com ênfase na presença do oxigênio, essencial à vida.

Na década de 1930, surgiu a primeira edição da Meteorologia brasileira, de Sampaio Ferraz, tratando de inúmeros temas constituintes das ciências atmosféricas. Os mapas do Brasil dentro dos livros escolares ganharam maior destaque, especialmente com a distinção de cada região do país. Mas, mesmo assim, as críticas hoje conhecidas à sociedade de consumo e ao esgotamento dos recursos naturais devido à ação humana sobre o planeta ainda não eram comuns nos livros escolares nem na imprensa.

Vários livros escolares dedicados a crianças e jovens também continham o pressuposto de um Brasil rico em recursos naturais e, ao mesmo tempo, disponível à exploração mineral e vegetal. O país e também o planeta tendiam a ser vistos a partir da ótica de uma suposta infinitude da natureza, juntamente com uma superioridade da cultura branca imaginada por uma elite letrada. Nesse aspecto, Aroldo de Azevedo, catedrático de Geografia do Brasil e professor da USP, representa um dos autores célebres dos livros de geografia dedicados aos estudantes brasileiros nos quais algumas questões do clima mostram uma concepção típica da época acerca das "raças" constituintes do país. Por exemplo, no livro intitulado Geografia humana do Brasil, destinado ao terceiro ano do curso colegial da década de 1950, a posição geográfica brasileira bem como as suas fronteiras fazem parte do primeiro capítulo, cuja inspiração evolucionista fornece um tom otimista à caracterização do meio. As bases humanas, físicas e econômicas aparecem distinguidas em momentos específicos da obra e o "Brasil do amanhã" é ilustrado com a fotografia do rosto de um menino sorridente e o seguinte comentário: "A maioria da população brasileira descende próxima ou remotamente de europeus de cor branca". E completa o comentário dizendo que "essa predominância tende a tornar-se com o tempo, cada vez maior" (AZEVEDO, 1951, p. 98).

No mesmo período, o livro de Attayde, intitulado Geografia do Brasil, destinado à quarta série ginasial, trata basicamente da geografia em cada região, tendência que se repete em vários outros livros escolares entre as décadas de 1940 e 1960. A flora amazônica ganha maior espaço nos livros desse período, assim como o clima da região norte do país. O livro possui um capítulo intitulado "Como medir e observar as 
condições atmosféricas", quando, então, o autor explica qual é a função da meteorologia: "observar, informar, prever e avisar" (ATTAYDE, 1951, p. 8). E o que querem os meteorologistas? Querem, segundo Attayde, descobrir a temperatura e a pressão do ar, a direção e a velocidade do vento, a umidade, a quantidade e o tipo das nuvens, a quantidade de chuva ou de neve, assim como as condições de visibilidade. Também, aqui, o ensino de uma consciência ecológica diante do esgotamento dos recursos naturais ainda é tênue, praticamente inexistente. A visão da natureza brasileira permanece delineada segundo um ufanismo típico do período em relação à grandeza dos recursos naturais nacionais.

Voltando à revista Tico-Tico, interessante observar a frequência com que o medo das tempestades, raios ou das chuvas fortes ocupou um lugar de destaque nas estórias e pequenas lições publicadas entre 1910 e 1930. Tratava-se de um medo considerado normal e que pedia precauções para a proteção dos corpos. Contudo o medo das temperaturas extremadas não expressava ainda alguma relação com a ação predatória dos humanos sobre o planeta.

Em 1938, com a criação da Comissão Nacional do Livro Didático, afirmou-se a tendência em cultivar brasileiros afinados com a política vigente, permanecendo a valorização dos contrastes existentes no planeta Terra, entre temperaturas, relevos e fauna, assim como o imaginário de uma natureza que estaria totalmente à disposição da exploração e dos interesses humanos.

\section{O Ser Humano Agente do Meio e Responsável por Ele}

As tendências rapidamente indicadas acima tendem a ser modificadas a partir de meados do século XX, principalmente entre 1970 e 1980. É quando os livros escolares de geografia e de ciências começaram a registrar, cada vez mais claramente, o fato de o ser humano intervir nos desígnios naturais e, portanto, ser ele próprio o responsável pelos rumos da flora e da fauna do planeta. Ou seja, se, durante as primeiras décadas do século XX, a maior parte das informações climáticas presentes na imprensa e nos livros escolares ancorava-se na antiga suposição de que o ser humano sofre as influências do meio, mais do que age sobre elas, a partir da década de 1950, houve uma inversão. Desde então, os dados climáticos, oriundos das mensurações da temperatura atmosférica, tornaram-se um tema amplamente discutido na imprensa, em reuniões científicas e também no âmbito da educação escolar, considerando a ação dos seres humanos sobre o planeta. Essa espécie de nova consciência da ação humana sobre a natureza teve vários momentos. Entre eles, há pelo menos três que vale aqui rapidamente destacar:

O primeiro ocorreu logo após a Segunda Guerra Mundial, quando a meteorologia sofreu um grande avanço devido à necessidade de determinar rotas de voo, de navegação e de definir estratégias militares. Nesse período, foram realizadas as primeiras sondagens atmosféricas, permitindo descobrir a estrutura e o funcionamento da alta atmosfera, assim como a sua influência sobre as mudanças de temperatura. $\mathrm{O}$ radar meteorológico foi desenvolvido a partir do radar militar, pois, em dias de chuva, as imagens ficavam mais difusas. Essas melhorias na observação atmosférica, complementadas décadas depois pelo desenvolvimento dos satélites meteorológicos, foram acompanhadas pelo surgimento de novas teorias que tinham a finalidade de explicar o funcionamento dos sistemas de tempo. Na imprensa brasileira, começou a haver um novo tipo de preocupação com a "couraça protetora da terra", ou seja, com a massa atmosférica que garantia a saúde do planeta. Em vários livros escolares, a atmosfera ganhou um lugar de destaque no ensino das ciências e da geografia, não mais como couraça e sim como uma proteção sob ameaça humana. $\mathrm{O}$ ensino das disciplinas de geografia e ciências sofreu alterações importantes. Com o risco nuclear durante a Guerra Fria, a ideia de que é necessário incorporar o meio ambiente como um ator importante na seara política e educacional favoreceu novos estudos capazes de reunir questões de ordem social e natural. 
As décadas de 1970 e 1980 podem ser consideradas um segundo momento dentro da mudança responsável por colocar os seres humanos como responsáveis pelo meio ambiente. Trata-se de um período de grandes eventos internacionais, com a criação da "Carta de Belgrado", em 1975, estabelecendo princípios e diretrizes para a educação ambiental. Criou-se um campo de saberes relacionados à ecologia e ao clima que passou a influenciar a produção de conhecimento em praticamente todas as demais áreas científicas. No Brasil, a primeira vez que a educação ambiental apareceu na legislação de forma integrada foi em 1981, com uma lei que instituiu uma Política Nacional de Meio Ambiente (RUMENOS, 2016). Desde então, os seres humanos deixam de ser vistos como submissos aos desígnios da natureza ou com capacidades menores do que as forças climáticas. Ao mesmo tempo, o tema da ecologia alcançou uma importância inédita nos meios de comunicação de massa e em numerosas propostas educacionais.

Paralelamente, houve nesse período uma profissionalização da indústria editorial, alterando profundamente a forma e o conteúdo dos livros didáticos (MUNAKATA, 2007). Os Guias curriculares para o estado de São Paulo também contribuíram para estabelecer novas diretrizes aos livros didáticos, com o aumento do número das imagens e a melhoria de sua qualidade, assim como de mapas e de informações sobre as variações climáticas. Inúmeros trabalhos escolares tenderam a ser realizados com o intuito de desenvolver uma consciência ecológica entre crianças e adultos capaz de provocar mudanças nos hábitos de consumo e nos comportamentos junto à natureza. O livro didático seria, assim, mais um agente entre as numerosas campanhas, atividades recreativas, esportivas e científicas voltadas para uma nova perspectiva ecológica, respeitosa da vida no planeta.

Um terceiro momento, posterior à década de 1990, refere-se à divulgação do fim de um período recente da Terra, o antropoceno. Desordens climáticas, aquecimento global, ameaças ao meio ambiente que revelam o risco do desaparecimento definitivo de diferentes plantas e animais - tornaram-se assuntos recorrentes em debates dentro e fora dos congressos internacionais sobre o clima. $\mathrm{O}$ antropoceno, considerado uma nova era geológica - diretamente relacionada à necessidade de uma mudança dos hábitos de produção e consumo, além de transformações profundas na relação entre humanos e não humanos - inspirou pesquisadores de diferentes áreas do conhecimento, assim como novas campanhas educacionais. Ameaças à vida e ao próprio planeta não cessaram desde então de caracterizar manifestações e ativismos em vários países, inclusive no Brasil.

Por conseguinte, as maneiras de perceber a natureza entre crianças e adultos tenderam a ser atravessadas por uma nova sensibilidade avessa a muitos dos antigos hábitos de consumo e de tratamento da flora e da fauna.

\section{A Terra, Uma Mãe Doente e Frágil}

A guinada no imaginário da Terra, ocorrida por volta das décadas de 1960 e 1970, retirou o lar e a origem da humanidade da garantia de que existem recursos naturais infinitos. A Terra, que durante séculos figurou no imaginário social ora como mãe dadivosa ou morada intocável ora como potência selvagem e rebelde aos domínios dos humanos, passou a ser vista como uma espécie paciente acamado, doente frágil e debilitado, que necessita de muitos cuidados para não morrer. Na Europa, a década de 1970 marcou a entrada da ecologia na política. Surgiram partidos políticos com a bandeira ecológica explicitamente transformada em proposta de governo (DUPUY, 2004). Doravante, a Terra tende a ser vista como morada exaurida e com recursos finitos, o que, sem dúvida, tem consequências psíquicas e sociais profundas e que ainda não foram totalmente esclarecidas. 
Justamente quando a própria ecologia se transformou em campo científico internacional de produção de conhecimento e de base às políticas públicas, o planeta Terra passou a ser um lugar poluído, saqueado por mineradoras, e massacrado pelo turismo de massas. Desde a década de 1970, os livros didáticos e a imprensa divulgam que a Terra é um ecossistema e que dentro dele há o efeito estufa, a poluição do ar e das águas provocada pelos humanos. A Terra se transformou, de modo mais evidente do que no passado, em um "lugar comum", vítima dos humanos, morada em vias de ser destruída e que demanda a responsabilidade de todos. Ao invés de enfatizar seus perigos naturais, sublinha-se o cuidado que se deve ter com os riscos climáticos, frutos do modo de vida industrial dos humanos.

Mais tarde, quando uma declaração de princípios intitulada Carta da Terra foi estabelecida, as ideias do ecossistema e da morada comum foram fortalecidas e somadas ao alerta de lutar pela paz e pela união dos povos e etnias. Em diversos contextos escolares, as crianças foram chamadas para atuarem como agentes de um mundo que demanda cuidados ecológicos diários. Aprender a ler o tempo tornou-se, portanto, um ato eminentemente político e que implica salvar o planeta e não piorar ainda mais a sua saúde.

Em 27 de abril de 1999, foi instituída a Política Nacional de Educação Ambiental. Ela estabeleceu que a educação ambiental deve ocorrer em todos os níveis, em caráter formal e não formal. As instituições educativas foram chamadas a criar programas para a conscientização dos alunos das graves ameaças da vida humana sobre a Terra e os meios de comunicação de massa foram levados a cooperar com o mesmo intuito. Na mesma época, a palavra "catástrofe" se tornou imperativa nas lições e aulas ligadas aos cuidados com o meio ambiente. Na verdade, uma "era da catástrofe" começou a ser objeto de denúncias e de pesquisas especialmente após o acidente nuclear de Chernobil, em abril de 1986.

Resta que, no Brasil - país cujo mito fundador está em grande medida assentado na imagem de um "jardim do paraíso" (CHAUÍ, 2000), detentor de uma rica natureza, "gigante pela própria natureza” aquelas tendências podem ter um impacto singular. Isso porque aceitar a condição da Terra como uma "morada" dependente, agora mais do que nunca, dos cuidados humanos ainda é particularmente difícil em sociedades nas quais prevalece o imaginário de que rios, mares, terras, flora e fauna, continuarão sempre potentes, resistentes e saudáveis, independentemente do que se faça com eles. Entretanto, desde a virada do milênio e, principalmente nos últimos anos, não cessa de crescer uma nova disposição - vinda inclusive de crianças e jovens - voltada à proteção ambiental e à mudança de hábitos, revelando o quanto a aliança entre o mundo natural e o desenvolvimento das sensibilidades humanas ingressou, efetivamente, numa nova era.

\section{Notas}

1. Felix Junius, in Correio Paulistano, 7 jul. 1872.

2. Diário de S. Paulo, 24 jan. 1975, p. 2.

3. Tico-Tico, 9 out. 1907.

4. Tico-Tico, 30 mar. 1910.

\section{REFERÊENIAS}

ATTAYDE, A. M. Geografia do Brasil. São Paulo: Companhia Ed. Nacional, 1951. 
AZEVEDO, A. Geografia Humana do Brasil. 10. ed. São Paulo: Ed. S/A., 1951.

BIBLIOTECA NACIONAL DIGITAL. O tico-tico. Hemeroteca da Biblioteca Nacional, 2015. Disponível em: https://bndigital.bn.gov.br/artigos/o-tico-tico/. Acesso em: 20 fev. 2020.

BOIA, L. The Weather in the Imagination. Londres: Reaktion Books, 2005.

CHAUÍ, M. O que comemorar? Projeto História, São Paulo, v. 20, p. 35-62, 2000.

CORBIN, A. La pluie, le soleil et le vent. Une histoire de la sensibilité au temps qu’il fait. Paris: Aubier, 2013.

CORBIN, A.; Courtine, J.-J.; Vigarello, G. Histoire des émotions. Paris: Seuil, 2016.

DUPUY, M. Les cheminements de l'écologie en Europe: Une histoire de la diffusion de l'écologie au miroir de la forêt, 1880-1980. Paris: L'Harmattan, 2004.

FEBVRE, L., La Sensibilité et l'Histoire: Comment reconstituer la vie affective d'autrefois? Annales D’histoire Sociale, França, v. 3, n. 1-2, p. 5-20, 1941. https://doi.org/10.3406/ahess.1941.3053

GOLINSKI, J. British weather and the climate of enlightenment. Chicago: University of Chicago, 2007. https://doi.org/10.7208/chicago/9780226302065.001.0001

JANKOVIC, V. Reading the skies: a cultural history of English weather, 1650-1820. Chicago: University of Chicago, 2000.

LADURIE, E. R. Histoire du climat depuis l’an mil. Paris: Flammarion, 1967.

MUNAKATA, K. História que os livros didáticos contam, depois que acabou a ditadura militar no Brasil. In: FREITAS, M. C. (Org.). Historiografia brasileira em perspectiva. 6 ed. São Paulo: Contexto, 2007.

POLITO, R.; LOPES, M. B. Posfácio. In: MACEDO, J. M. Considerações sobre a nostalgia. Campinas: Editora da Unicamp, 2004.

PRADO, A. A. Crônica de outrora. São Paulo: Brasiliense, 1963.

REDDY, W. M. The Navigation of Feeling: A Framework for the History of Emotions. Cambridge: Cambridge University, 2001.

ROSENWEIN, B. H. História das Emoções: problemas e métodos. São Paulo: Letra e Voz, 2011.

RUMENOS, N. N. O tema mudanças climáticas nos livros didáticos de ciências da natureza para o ensino fundamental II: um estudo a partir do PNLD 2014. 2016. 157f. Dissertação (Mestrado em Educação) Universidade Estadual Paulista, Rio Claro, 2016. Disponível em: https://repositorio.unesp.br/bitstream/ handle/11449/144536/rumenos_nn_me_rcla.pdf? sequence=3\&isAllowed=y. Acesso em: 24 jul. 2020. 
SANT'ANNA NETO, J. L. História da Climatologia no Brasil: Gênese, Paradigmas e a Construção de uma Geografia do Clima. 2001. 52f. Tese (Livre-Docência) - Universidade Estadual Paulista, Presidente Prudente, 2001.

SANT'ANNA, D. B. Com 2 livros já lançados, 'Histoire des Émotions' cobre um vasto período da humanidade. Trajetória da obra começa na Antiguidade clássica. O Estado de S. Paulo, São Paulo, 2 dez. 2016.

SIGAUD, J. F. X. Du climat et des maladies du Brésil ou Statistique médicale de cet Empire. Paris: Chez Fortin, Masson et Cia, Librairies, 1844.

VIGARELLO, G. Le Sentiment de soi: Histoire de la perception du corps (XVIe-XXe siècle). Paris: Du Seuil, 2014.

Recebido: 30 ago 2019

Aceito: 10 fev 2020

Comitê Editorial dos Cadernos Cedes/Coordenação deste número:

Alessandra Arce Hai e Ana Clara Bortoleto Nery 